\title{
COMPORTAMENTO DO FOGO EM QUEIMAS CONTROLADAS DE VEGETAÇÃO DE ESTEPE NO MUNICÍPIO DE PALMEIRA, PARANÁ, BRASIL
}

\author{
Celso Darci Seger ${ }^{1}$, Antonio Carlos Batista ${ }^{2}$, Alexandre França Tetto ${ }^{2}$, Ronaldo Viana Soares ${ }^{2}$ \\ ${ }^{1}$ Biólogo, Doutorando em Eng. Florestal, UFPR, Curitiba, PR, Brasil, celsoseger@terra.com.br \\ ${ }^{2}$ Eng. Florestal, Dr., Depto. de Ciências Florestais, UFPR, Curitiba, PR, Brasil, batistaufpr@ufpr.br; tetto@ufpr.br; \\ rvsoares@ufpr.br
}

Recebido para publicação: 05/04/2013 - Aceito para publicação: 11/09/2013

\begin{abstract}
Resumo
As queimas controladas constituem práticas de manejo utilizadas em diferentes tipos de vegetação e difundidas em vários países. No entanto, para a realização de tais práticas com segurança e eficiência é fundamental o conhecimento do comportamento do fogo. O objetivo desse trabalho foi caracterizar o comportamento do fogo em queimas controladas de vegetação Estepe Gramíneo-Lenhosa no estado do Paraná. Para isso, foi instalado um experimento no município de Palmeira, onde 20 parcelas foram queimadas, sendo metade a favor e metade contra o vento. A carga de material combustível fino estimada foi de $2,26 \mathrm{~kg} \cdot \mathrm{m}^{-2}$, com teor médio de umidade de $50,45 \%$. A quantidade de material consumido pela queima foi de $1,76 \mathrm{~kg} \cdot \mathrm{m}^{-2}$, com uma eficiência média de queima de $76,86 \%$. As médias obtidas, a favor e contra o vento, foram respectivamente: velocidade de propagação do fogo de 0,049 e $0,012 \mathrm{~m} \cdot \mathrm{s}^{-1}$, altura das chamas de 1,34 e $0,843 \mathrm{~m}$, intensidade do fogo de 210,53 e 50,68 $\mathrm{kcal} . \mathrm{m}^{-1} \cdot \mathrm{s}^{-1} \mathrm{e}$ calor liberado de $4.067,19 \mathrm{e} 4.508,92 \mathrm{kcal} . \mathrm{m}^{-2}$. Os resultados permitiram concluir que as queimas controladas em vegetação de campos naturais, realizadas dentro dos critérios estabelecidos de planos de queima, são viáveis e seguras sob o ponto de vista de perigo de incêndios.

Palavras chave: Queima prescrita; material combustível; intensidade do fogo; perigo de incêndios.
\end{abstract}

\begin{abstract}
Fire behavior of prescribed burns in grassland on Palmeira county, Paraná, Brazil. The prescribed burns are practices of management used in different types of vegetation and widespread in several countries. However, to carry out such practices safely and effectively is fundamental knowledge of fire behavior. The aim of this study was to characterize the fire behavior in controlled burning of grassland vegetation in Paraná state. For this, an experiment was conducted in Palmeira County, where 20 plots were burned, half in favor and half against the wind. The estimated fine fuel loading was $2.26 \mathrm{~kg} . \mathrm{m}^{-2}$, with average moisture content of $50.45 \%$. The fuel consumption by burning was $1.76 \mathrm{~kg} \cdot \mathrm{m}^{-2}$ with an average efficiency of burning of $76.86 \%$. The averages, for and against the wind, were: speed of fire spread of 0.049 and $0.012 \mathrm{~m}^{-1} \mathrm{~s}^{-1}$, the flame height of $1.34 \mathrm{~m}$ and 0.843 , fire intensity of 210.53 and $50.68 \mathrm{kcal} . \mathrm{m}^{-1} \cdot \mathrm{s}^{-1}$ and heat released from 4,067.19 and 4,508.92 kcal. $\mathrm{m}^{-2}$. The results show that the controlled burnings of grasslands vegetation, carried out within the established criteria burning plans are feasible and safe from the aspect of fire danger.

Keywords: Prescribed burns; fuel loading; fire intensity; fire risk.
\end{abstract}

\section{INTRODUÇÃO}

Dentre os diversos agentes que provocam danos à natureza, o fogo tem um papel destacado, seja pelos danos provocados aos diferentes tipos de vegetação e fauna associada, como também, pela degradação do solo. O fogo, no entanto, não representa apenas um agente causador de danos, mas, pode também trazer benefícios a determinados ecossistemas, desde que, utilizado de forma controlada, ou seja, por meio de queimas controladas que propiciem o manejo da vegetação sem comprometer os processos naturais de regeneração (SOARES, 1995). 
As queimas controladas ou queimas prescritas constituem práticas de manejo utilizadas em diferentes tipos de vegetação e difundidas em vários países. Dentre outros objetivos, visam diminuir a carga de material combustível que pode gerar incêndios mais destrutivos durante períodos mais críticos, manejar a vegetação de pastagens, controlar pragas e doenças e promover a limpeza de terrenos para culturas agrícolas e florestais. Consistem no uso do fogo de forma confinada a uma área selecionada e em condições climáticas adequadas, de forma que a intensidade do fogo e a taxa de propagação alcancem os objetivos de manejo que se pretende numa vegetação qualquer (SOARES; BATISTA, 2007).

Para a realização de queimas controladas, é importante que se tenha informações a respeito do comportamento do fogo sobre determinada vegetação. Segundo Souza et al. (2003) informações referentes ao comportamento do fogo são importantes tanto para o manejo, como também, para o planejamento de operações de combate a incêndios.

Comportamento do fogo é um termo genérico utilizado para descrever as principais características da combustão em um incêndio florestal ou uma queima. Refere-se também à forma como o material entra em combustão, como se desenvolvem as chamas, como o fogo se propaga e apresenta outros fenômenos. O estudo do comportamento do fogo possibilita entender os fatores que têm um papel importante no início e na propagação do fogo, além do combate aos incêndios. Basicamente, as variáveis que descrevem o comportamento do fogo são: velocidade de propagação, intensidade, taxa de energia liberada e tempo de residência. Essas variáveis quantificam e caracterizam o comportamento do fogo, bem como controlam a dificuldade de extinção de qualquer incêndio (VEGA, 1996). Outras variáveis como temperaturas máximas alcançadas nas zonas de combustão e altura de crestamento letal, além de descrever aspectos do comportamento do fogo, possibilitam estabelecer associações com o efeito produzido nos diversos elementos do ecossistema florestal (DE RONDE et al., 1990).

O comportamento do fogo é o resultado da interação entre meteorologia, condições do combustível, topografia, técnica de queima e forma de ignição. As variáveis que descrevem o comportamento do fogo são úteis para comparar queimas, para o planejamento da supressão e para avaliar os efeitos do fogo (SOARES; BATISTA, 2007).

Um dos usos mais comuns da queima controlada é para a renovação de pastagens. Essa prática teve início há milhares de anos, quando os primeiros pastores notaram que após a queima, a vegetação se reestabelecia com mais nutrientes, o que beneficiava o desenvolvimento dos animais. A partir de então, tornou-se uma prática rotineira utilizada no manejo de pastagens, sendo ainda praticada em muitas regiões do mundo (SOARES, 1995).

No território brasileiro, a maioria dos biomas está sujeito a queimas em maior ou menor escala (PIVELLO, 2011), sendo as savanas (Cerrados) juntamente com as Estepes (Campos Sulinos), os que são manejados com maior frequência com o uso do fogo. A renovação do pasto nativo das estepes por meio do fogo é uma das práticas muito comuns em diversas regiões do Brasil. No estado do Paraná, os campos naturais, presentes na região denominada de Campos Gerais e descritos por Maack (1981) como "estepe de gramíneas baixas", ocorrem principalmente no Segundo Planalto, estendendo-se desde o município de Rio Negro (divisa com Santa Catarina) até Sengés na divisa com o estado de São Paulo, inserindo-se na região da Estepe Ombrófila (LEITE, 2002).

Durante muitos anos, a estepe paranaense foi utilizada como pastagem para criação intensiva de gado bovino, sendo anualmente manejada por meio de queimas. Atualmente, essa atividade econômica perdeu força na região, e os campos estão sendo gradativamente convertidos em áreas de agricultura e silvicultura, além da ocupação pela expansão urbana. No entanto, porções de campos ainda são mantidas nas fazendas na forma de Áreas de Reserva Legal, que muitas vezes são utilizadas para criação de gado ou ovinocultura. Embora a queima da vegetação campestre ainda seja uma prática comum de manejo dessas áreas na região, não há, no entanto, informações a respeito do comportamento do fogo nesse tipo de vegetação.

Considerando-se a hipótese de que a queima controlada é uma atividade viável e segura para o manejo da pastagem, o objetivo dessa pesquisa foi caracterizar o comportamento do fogo em vegetação de estepe do estado do Paraná, em queimas controladas, para subsidiar estudos dos efeitos do fogo sobre a sobrevivência e regeneração das espécies que compõem esse ambiente. 


\section{MATERIAL E MÉTODOS}

\section{Área de estudo}

Os experimentos foram realizados na Reserva Particular do Patrimônio Natural (RPPN) Caminho das Tropas, com coordenadas centrais de UTMs 620334 E e 7196739 S, município de Palmeira. Cabe destacar que por se tratar de uma RPPN estadual, este estudo foi realizado mediante a autorização de pesquisa $\mathrm{n}^{\circ} 470.131$ do Instituto Ambiental do Paraná (IAP).

A Reserva foi criada em 2008 pela portaria de $\mathrm{n}^{\circ}$ 188/08 (IAP, 2013), possui área de 189,70 hectares e faz parte da Fazenda Santa Rita. Anteriormente à criação da RPPN, a área era utilizada para pastagem, vegetação manejada anualmente por meio do fogo. As queimas eram feitas sempre após o inverno, entre os meses de agosto e setembro. A partir de 2005 a área foi abandonada e, após alguns anos de repouso, a vegetação nativa típica de Estepe se reestabeleceu.

De acordo com a classificação de Köppen, o clima regional onde se insere a área de estudo é do tipo $\mathrm{Cfb}$, presente nas porções mais elevadas dos planaltos do estado do Paraná. Nesse clima, caracterizado como temperado, as chuvas são uniformemente distribuídas, com verões frescos apresentando temperaturas médias inferiores a $22{ }^{\circ} \mathrm{C}$ e invernos frios com médias abaixo de $18{ }^{\circ} \mathrm{C}$. Geadas severas são frequentes, num período médio de ocorrência de 10 a 25 dias anualmente (INSTITUTO AGRONÔMICO DO PARANÁ (IAPAR), 2013). O vento sopra predominantemente do sentido nordeste.

\section{Estabelecimento de parcelas}

O local escolhido para o experimento está localizado no limite sudoeste da RPPN, em terreno plano, o que possibilitou a realização das queimas da vegetação sem que houvesse interferências da declividade.

Para a montagem do experimento foram estabelecidas 20 parcelas com dimensões de $3 \mathrm{~m}$ x $20 \mathrm{~m}$ $\left(60 \mathrm{~m}^{2}\right)$, dispostas na direção predominante do vento da região (sentido nordeste). Em todas as parcelas foram fixadas estacas de madeiras de $1,20 \mathrm{~m}$ de altura a cada $2 \mathrm{~m}$, servindo como pontos de observações de dados do comportamento do fogo (Figura 1). Em cada parcela foram efetuadas observações e medições sobre o material combustível, variáveis meteorológicas e, durante as queimas, sobre o comportamento do fogo. Para prevenção de alastramento do fogo foram feitos aceiros de 3 metros de largura no entorno das parcelas, com a utilização de roçadeira anexada a um trator. Além dessa medida de prevenção, uma equipe de apoio composta por funcionários da fazenda e estagiários do laboratório de incêndios florestais da Universidade Federal do Paraná - UFPR acompanhou os experimentos, ficando de prontidão para entrar em ação no caso de uma possível perda de controle do fogo, utilizando equipamentos manuais de combate a incêndios florestais.

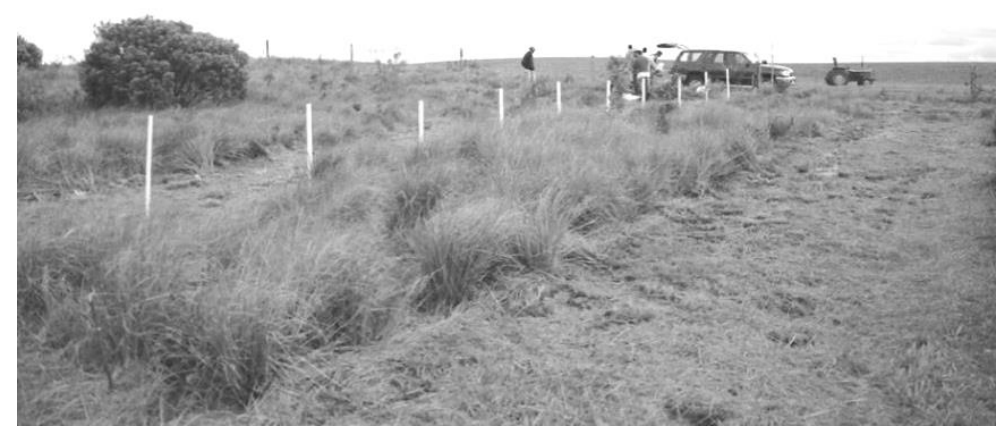

Figura 1. Demarcação de parcelas para montagem do experimento.

Figure 1. Field plot delineation.

\section{Monitoramento das condições meteorológicas}

Durante o período do experimento, as condições meteorológicas foram monitoradas continuamente por meio de uma estação meteorológica portátil Watchdog 2000, com datalogger para 
armazenamento dos dados, e ajustada para leitura da temperatura, umidade relativa, velocidade e sentido do vento de minuto em minuto, instalada cerca de $300 \mathrm{~m}$ do local das queimas. Durante as queimas também foram feitas observações meteorológicas junto às parcelas que foram queimadas. Antes da realização das queimas em cada parcela, foram anotadas a velocidade média do vento $\left(\mathrm{m} . \mathrm{s}^{-1}\right)$, a temperatura $\left({ }^{\circ} \mathrm{C}\right)$ e a umidade relativa do ar $(\%)$, utilizando a estação automática Kestrel 6000 Pocket Weather Station, a uma altura média de 1,20 metros acima do solo. Dados referentes à pluviometria dos dias anteriores à queima foram obtidos da estação meteorológica da localidade de Rosário, município de Ponta Grossa, cujos resultados encontram-se à disposição para consulta no website da Fundação $\mathrm{ABC}$ (FUNDAÇÃO ABC, 2013).

\section{Caracterização do material combustível}

Foram levantadas informações sobre o tipo, a quantidade e o conteúdo de umidade do material combustível. Esses dados foram obtidos por meio do inventário do material combustível superficial fino presente na área (material vegetal vivo ou morto presente na parcela até $1,80 \mathrm{~m}$ de altura e com diâmetro menor do que $0,7 \mathrm{~cm}$ ). Para isso foram alocadas, aleatoriamente em cada parcela, 3 amostras de $400 \mathrm{~cm}^{2}$ $(20 \mathrm{~cm} \times 20 \mathrm{~cm})$ cada uma, de onde o material foi coletado. Após coletado, o material foi imediatamente acondicionado em sacos plásticos, que foram vedados para evitar a perda de umidade (Figura 2). Em seguida esse material foi submetido à secagem em estufas elétricas no laboratório de incêndios florestais da UFPR, durante um período de 48 horas em temperatura constante de $75^{\circ} \mathrm{C}$.

Para a determinação do teor de umidade do material combustível foi empregada a seguinte fórmula (BATISTA, 1990):

$$
U \%=\left(\frac{M u-M s}{M s}\right) * 100
$$

Em que: $\mathrm{U} \%$ = teor de umidade do material combustível em \%;

$\mathrm{Mu}=$ massa do material fresco no momento da coleta em grama;

$\mathrm{Ms}=$ massa do material combustível seco em estufa em grama.
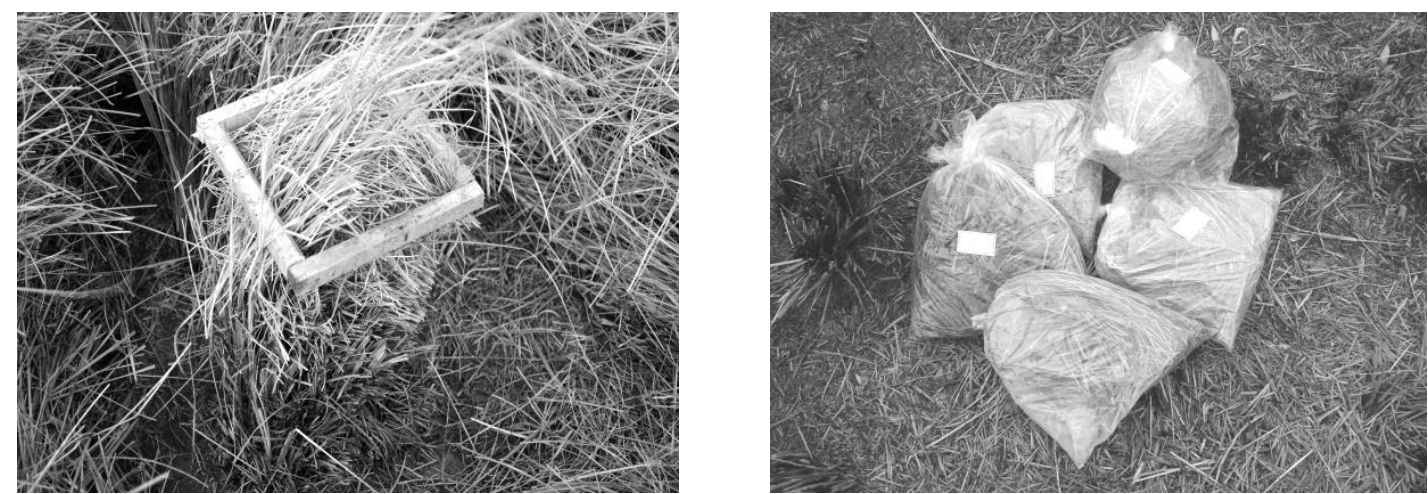

Figura 2. Caracterização do material combustível.

Figure 2. Fuel loading characterization.

\section{Queima das parcelas}

As queimas (Figura 3) foram feitas após o inverno, em 29 de setembro, 02 e 04 de outubro de 2012. Os horários escolhidos foram entre as $14 \mathrm{~h} 00 \mathrm{~min}$ e $18 \mathrm{~h} 30 \mathrm{~min}$, período do dia em que a velocidade do vento é menor, com consequente redução dos riscos de perda de controle do fogo e possibilidade de propagação para áreas do entorno do experimento. Durante as três referidas datas, a direção do vento permaneceu constante no sentido nordeste.

As últimas chuvas antes da realização do experimento ocorreram em 21 e 25 de setembro de 2012, com precipitações de $23 \mathrm{~mm}$ e 1,6 mm respectivamente (FUNDAÇÃO ABC, 2013). Dessa forma, as queimas ocorreram com 4, 7 e 9 dias após a última precipitação, abrangendo um período considerado 
relativamente seguro para queimas, ou seja, até 10 dias desde a última chuva, quando o grau de perigo de incêndios ainda não alcançou os níveis críticos (SOARES; BATISTA, 2007).

Foram utilizadas duas técnicas de queima (dois tratamentos): queima contra e queima a favor do vento. Para a ignição do fogo foi utilizado um lança-chamas do tipo "pinga-fogo", marca Guarany, contendo líquido inflamável composto de mistura de óleo diesel com gasolina, na proporção de 3 para 1.
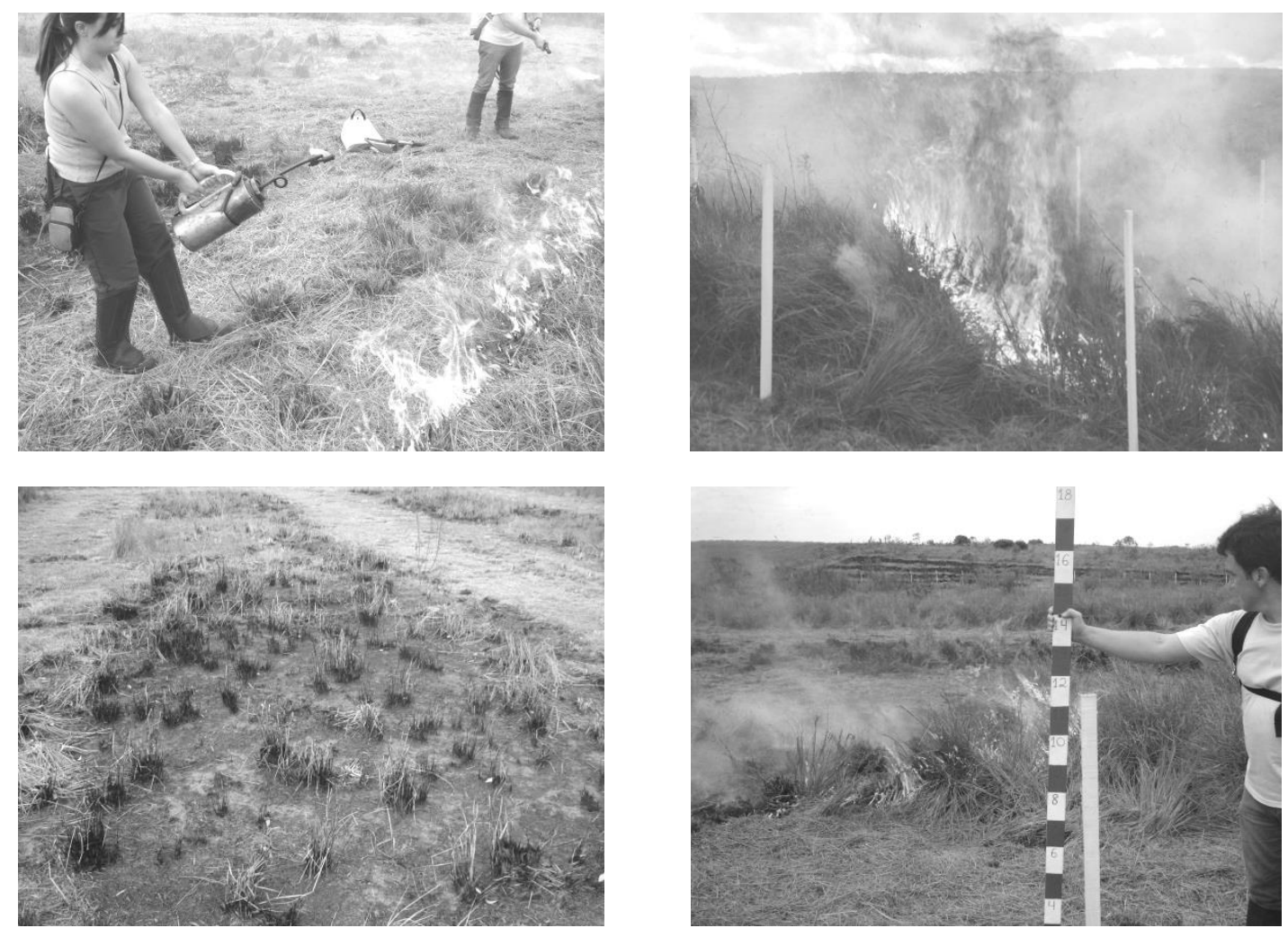

Figura 3. Sequência de imagens de queima das parcelas e anotação de dados do comportamento do fogo.

Figure 3. Pictures of burned plots and record data of fire behavior.

\section{Variáveis do comportamento do fogo}

Durante a queima de cada parcela, foram feitas observações sobre as seguintes variáveis do comportamento do fogo, conforme procedimentos padrão adotados internacionalmente e recomendados por diversos autores (KUÇUK et al., 2008; RIBEIRO et al., 2006; GARNICA et al., 2006):

- velocidade de propagação - obtida visualmente, determinando-se o tempo necessário para a linha de fogo percorrer distâncias de $2 \mathrm{~m}$, previamente demarcadas em cada parcela, no sentido do seu comprimento (20 m);

- altura das chamas - estimativa visual da altura média alcançada pelas chamas a cada $2 \mathrm{~m}$ de avanço da linha de fogo, com o auxílio de comparadores (escalas) de dimensões conhecidas.

Utilizando-se as variáveis obtidas no momento das queimas descritas anteriormente, juntamente com as informações da bibliografia, calculou- se as seguintes variáveis:

- intensidade do fogo - estimada pela equação proposta por Byram (1959):

$$
I=H \cdot w \cdot r
$$

Em que: $\mathrm{I}=$ intensidade do fogo em kcal. $\mathrm{m}^{-1}$;

$\mathrm{H}=$ poder calorífico em kcal. $\mathrm{kg}^{-1}$;

$\mathrm{w}=$ massa do combustível disponível em $\mathrm{kg} \cdot \mathrm{m}^{-2}$;

$\mathrm{r}=$ velocidade de propagação do fogo em $\mathrm{m} \cdot \mathrm{s}^{-1}$. 
Utilizou-se $\mathrm{H}=3875 \mathrm{kcal} . \mathrm{kg}^{-1}$ como poder calorífico de vegetação campestre, de acordo com proposta de Griffin e Friedel (1984). Considerando-se que há perda do poder calorífico devido o teor de umidade, foi feita a correção do valor de $\mathrm{H}$ em função do teor de umidade do combustível mediante a fórmula (SOARES; BATISTA, 2007):

$$
H_{w}=H_{d} *\left(\frac{100-\frac{u}{7}}{100+u}\right)
$$

Em que: $\mathrm{H}_{\mathrm{w}}=$ poder calorífico do material combustível úmido em kcal. $\mathrm{kg}^{-1}$;

$\mathrm{H}_{\mathrm{d}}=$ poder calorífico do material combustível seco em kcal.kg-1;

$\mathrm{u}=$ teor de umidade do material combustível em \%.

- calor liberado - o cálculo de calor liberado por unidade de área foi estimado por meio da fórmula:

$$
H_{a}=H * w
$$

Em que: $\mathrm{H}_{\mathrm{a}}=$ calor liberado em kcal.m $\mathrm{m}^{-2}$;

$\mathrm{H}=$ poder calorífico em kcal. $\mathrm{kg}^{-1}$;

$\mathrm{w}=$ massa do combustível consumido em $\mathrm{kg} \cdot \mathrm{m}^{-2}$.

\section{Processamento e análise dos dados}

A partir da coleta e processamento dos dados foi possível construir uma matriz composta de variáveis ambientais (combustível e condições meteorológicas) e variáveis do comportamento do fogo (Tabela 1).

Os dados obtidos, referentes ao ambiente (material combustível e condições meteorológicas) e ao comportamento do fogo, foram processados em planilhas (Microsoft Office Excel 2007) e analisados com o software STATGRAPHICS Centurion XV. Os testes estatísticos utilizados para análise e comparação dos dados foram: análise de variância e teste de comparação de médias Student-Newman-Keuls.

Tabela 1. Variáveis ambientais e do comportamento do fogo.

Table 1. Environmental variables and fire behavior.

\begin{tabular}{lll}
\hline Variável & Descrição & Unidade \\
\hline WCf & Material combustível antes da queima (média de 3 amostras/ parcela) & $\mathrm{kg} \cdot \mathrm{m}^{-2}$ \\
WCc & Material combustível residual (média de 3 amostras/ parcela) & $\mathrm{kg} \cdot \mathrm{m}^{-2}$ \\
$\mathrm{Hch}$ & Altura das chamas durante a queima (média de 10 observações por parcela) & $\mathrm{m}$ \\
T & Temperatura do ar no início da queima da parcela & ${ }^{\circ} \mathrm{C}$ \\
UR & Umidade relativa do ar no início da queima da parcela & $\%$ \\
$\mathrm{r}$ & Velocidade de propagação do fogo (média de 10 observações por parcela) & $\mathrm{m} \cdot \mathrm{s}^{-1}$ \\
Vv & Velocidade do vento no início da queima da parcela & $\mathrm{km} \cdot \mathrm{h}^{-1}$ \\
$\mathrm{I}$ & Intensidade do fogo (média de 10 observações por parcela) & $\mathrm{kcal} . \mathrm{m}^{-1} \cdot \mathrm{s}^{-1}$ \\
$\mathrm{H}_{\mathrm{a}}$ & Calor liberado por unidade de área & $\mathrm{kcal} . \mathrm{m}^{-2}$ \\
\hline
\end{tabular}

\section{RESULTADOS E DISCUSSÃO}

\section{Condições meteorológicas}

As condições meteorológicas verificadas nas datas em que se realizaram as queimas são apresentadas na tabela 2 .

Tabela 2. Condições meteorológicas nas datas de realização do experimento.

Table 2. Weather conditions during the experiment.

\begin{tabular}{llccc}
\hline \multirow{2}{*}{ Data } & \multirow{2}{*}{$\mathbf{N}$} & \multicolumn{3}{c}{ Médias das variáveis meteorológicas } \\
\cline { 3 - 5 } & & Temperatura $\left({ }^{(} \mathbf{C}\right)$ & Umidade relativa $(\%)$ & Velocidade do vento $\left(\mathbf{k m}^{\mathbf{1}} \mathbf{H}^{\mathbf{1}}\right)$ \\
\hline $29 / 09 / 2012$ & 7 & $14,4_{\mathrm{a}}$ & $69,0_{\mathrm{a}}$ & $15,5_{\mathrm{a}}$ \\
$02 / 10 / 2012$ & 9 & $26,2_{\mathrm{b}}$ & $56,0_{\mathrm{a}}$ & $7,5_{\mathrm{b}}$ \\
$04 / 10 / 2012$ & 4 & $23,0_{\mathrm{c}}$ & $66,0_{\mathrm{a}}$ & $8,2_{\mathrm{b}}$ \\
\hline
\end{tabular}

Nota: Médias seguidas pela mesma letra na coluna não diferem entre si, pelo teste Student-Newman-Keuls a 5\% de probabilidade. 
Com base nos dados da tabela 2, fica evidente que as condições meteorológicas variaram significativamente entre os três dias em que se realizaram as queimas. Apenas as médias da umidade relativa não variaram significativamente entre os dias analisados. Esta é uma das dificuldades verificadas normalmente quando se realiza experimentos de queima em ambiente aberto. No entanto, as condições meteorológicas se mantiveram muito próximas dos limites recomendados por diversos pesquisadores para realização de queimas com segurança (FERNANDES; LOUREIRO, 2010; SOARES; BATISTA, 2007; FERNANDES et al., 2002).

Tabela 3. Prescrição genérica para uso do fogo em vegetação arbustiva e herbácea.

Table 3. Fire prescription for shrub and herbaceous vegetation tipes.

\begin{tabular}{lccc}
\hline Elementos da prescrição & Ótimo & Mínimo & Máximo \\
\hline Condições meteorológicas: & & & \\
- Número de dias sem chuva & $3-7$ & 1 & 10 \\
- Temperatura em ${ }^{\circ} \mathrm{C}$ & $8-20$ & 5 & 25 \\
- Umidade relativa em \% & $30-70$ & 20 & 85 \\
- Velocidade do vento em km. ${ }^{-1}$ & $5-15$ & 1 & 20 \\
Comportamento do fogo: & & & \\
- Velocidade de propagação em m.s ${ }^{-1}$ & $0,03-0,08$ & $<0,03$ & 0,13 \\
- Comprimento das chamas em metro & $1-4$ & $<1$ & 5,5 \\
\hline
\end{tabular}

Fonte: Fernandes et al. (2002), modificado pelos autores.

Material combustível

As características do material combustível nas parcelas, antes e depois da queima, estão apresentadas na tabela 4 .

Tabela 4. Características do material combustível nas parcelas, antes e depois da queima.

Table 4. Fuel loading characteristics in the plots, before and after burning.

\begin{tabular}{cccccc}
\hline $\begin{array}{c}\mathbf{N}^{\circ} \text { de } \\
\text { parcelas }\end{array}$ & $\begin{array}{c}\text { Técnica de } \\
\text { queima }\end{array}$ & $\begin{array}{c}\text { Combustível } \\
\text { total }\left(\mathbf{k g . m} \mathbf{m}^{-2}\right)\end{array}$ & $\begin{array}{c}\text { Teor de } \\
\text { umidade } \\
(\boldsymbol{\%})\end{array}$ & $\begin{array}{c}\text { Combustível } \\
\text { consumido }\left(\mathbf{k g . m} \mathbf{m}^{-2}\right)\end{array}$ & $\begin{array}{c}\text { Combustível } \\
\text { consumido (\%) }\end{array}$ \\
\hline 10 & Favor do vento & 2,18 & 50,33 & 1,69 & 76,76 \\
10 & Contra o vento & 2,35 & 50,58 & 1,84 & 76,97 \\
\hline Média & & $\mathbf{2 , 2 6}$ & $\mathbf{5 0 , 4 5}$ & $\mathbf{1 , 7 6}$ & $\mathbf{7 6 , 8 6}$ \\
\hline
\end{tabular}

A média do material combustível total observado nas parcelas foi de 2,26 kg.m ${ }^{-2}$, não havendo diferença significativa entre parcelas demarcadas para as duas técnicas de queima, a favor e contra o vento.

Também não houve diferença estatisticamente significativa entre as técnicas de queima quando se comparou a quantidade de material consumido pelo fogo, que em média foi de $77 \%$ do material fino total. Essa variável descreve ou caracteriza a "eficiência da queima". A variação no consumo de material combustível tem ligação direta com fatores meteorológicos, tipo de vegetação e a relação entre o material vivo e morto. Os valores obtidos nesta pesquisa são compatíveis com os percentuais obtidos em queimas de vegetação herbácea de campos e savanas, que segundo Levine (1996) pode variar de 65 a 95\%. Para as Savanas do Brasil, Pivello e Coutinho (1992) encontraram valores de 63 e 77\%, enquanto Miranda et al. (1996) determinaram valores entre 81 e $94 \%$ para a mesma vegetação. Em vegetação de Estepe, Fidelis et al. (2010) registraram valores de $93 \%$ em área com cerca de dois anos sem queimas e de $95 \%$ em área com seis anos sem a passagem de fogo.

$\mathrm{O}$ teor médio de umidade do material encontrado para as 20 parcelas foi de aproximadamente $50 \%$, com variações entre 37,99 e $60,84 \%$, não havendo diferença estatística entre as técnicas de queima utilizadas. Basicamente, compunha-se de material fino $(\leq 0,7)$, que queima com facilidade, sendo assim classificado como material combustível perigoso (SOARES, 1985). Grande parte do material (aproximadamente $85 \%$ ) estava morto, apresentando teor médio de umidade de $48 \%$. Já o material vivo, representado por cerca de $15 \%$ da carga de material combustível, apresentou teor médio de umidade de 
127\%. Além da espessura e da proporção de material morto, também o arranjo do material (espaçado e não acamado) certamente influenciou para a quantidade de material consumido.

Os valores de umidade do combustível foram muito similares ao encontrados por vários pesquisadores ao analisar combustíveis de vegetação Estepe. Fidelis et al. (2010) registraram valores de teor de umidade entre 37,80 e 44,49\%, para o material fino em experimento de queima realizado com vegetação campestre (Estepe Estacional) próxima à cidade de Porto Alegre. Já Miranda et al. (1996) encontraram valores de 8 a $23 \%$ de umidade em material fino $(\leq 0,7 \mathrm{~cm})$ morto e de 113 a $163 \%$ em material vivo em vegetação de campos sujos de Cerrado na região de Brasília, sendo que mais de $70 \%$ do material fino era constituído de material morto. Pivello e Coutinho (1992) registraram teor de umidade de 21 a 44\% em vegetação de Campos Cerrados no interior do estado de São Paulo.

\section{Comportamento do fogo}

$\mathrm{Na}$ tabela 5 são apresentadas as variáveis do comportamento do fogo, obtidas durante o monitoramento das queimas a favor e contra o vento.

Tabela 5. Variáveis do comportamento do fogo em queimas controladas de vegetação de Estepe no município de Palmeira - PR.

Table 5. Fire behavior variables in prescribed fire of grassland vegetation in Palmeira - PR.

\begin{tabular}{lcccccc}
\hline \multirow{2}{*}{ Variáveis do comportamento do fogo } & \multicolumn{3}{c}{ Queima contra o vento } & \multicolumn{3}{c}{ Queima a favor do vento } \\
\cline { 2 - 7 } & Média & Mínimo & Máximo & Média & Mínimo & Máximo \\
\hline Velocidade de propagação em $\mathrm{m}_{\mathrm{s}} \mathrm{s}^{-1}$ & $0,012_{\mathrm{a}}$ & 0,006 & 0,017 & $0,049_{\mathrm{b}}$ & 0,043 & 0,054 \\
Altura das chamas em metro & $0,84_{\mathrm{a}}$ & 0,76 & 0,92 & $1,34_{\mathrm{a}}$ & 1,26 & 1,42 \\
Intensidade da frente de fogo em & $50,68_{\mathrm{a}}$ & 13,75 & 87,60 & $210,53_{\mathrm{b}}$ & 173,60 & 247,45 \\
$\mathrm{kcal} . \mathrm{m}^{-1} \cdot \mathrm{s}^{-1}$ & $4508,92_{\mathrm{a}}$ & 3818,26 & 5199,57 & $4067,19_{\mathrm{a}}$ & 3376,54 & 4757,84 \\
\hline Calor liberado em kcal.m $\mathrm{m}^{-2}$ & &
\end{tabular}

Nota: Médias seguidas pela mesma letra na linha não diferem entre si, pelo teste Student-Newman-Keuls a 5\% de probabilidade.

Houve diferença estatisticamente significativa na velocidade de propagação do fogo entre as técnicas de queima utilizadas. A velocidade média de propagação do fogo a favor do vento variou entre 0,043 e $0,054 \mathrm{~m} \cdot \mathrm{s}^{-1}$, média de $0,049 \mathrm{~m} \cdot \mathrm{s}^{-1}$, considerada como propagação média do fogo, de acordo com Soares e Batista (2007). Nas queimas realizadas contra o vento, a velocidade de propagação do fogo variou entre 0,006 e $0,017 \mathrm{~m} \cdot \mathrm{s}^{-1}$, com média de $0,012 \mathrm{~m} \cdot \mathrm{s}^{-1}$, velocidade de propagação classificada como lenta pelos autores citados anteriormente.

Em pesquisas sobre o comportamento do fogo em queimas controladas em pradarias no estado Oklahoma, Estados Unidos da América, Bidwell e Engle (1991) obtiveram valores de 0,20 e 0,02 m.s ${ }^{-1}$ para a velocidade de propagação do fogo em queimas a favor e contra o vento, respectivamente.

Fidelis et al. (2010) registraram velocidade média de propagação do fogo de $0,015 \mathrm{~m} \cdot \mathrm{s}^{-1} \mathrm{em}$ queimas a favor do vento, em vegetação campestre com um ano sem queimas, e de $0,013 \mathrm{~m} \cdot \mathrm{s}^{-1} \mathrm{em}$ área de campo com período de seis anos sem queima. No estudo de Miranda et al. (1996), os autores determinaram valores de velocidade da frente do fogo em campos sujos de Cerrado com variação de 0,13 a $0,64 \mathrm{~m} \cdot \mathrm{s}^{-1}$ (média de $0,385 \mathrm{~m} \cdot \mathrm{s}^{-1}$ ).

A queima contra o vento é a técnica de queima controlada mais simples e segura a ser utilizada, desde que exista vento constante, com velocidades entre 6 e $16 \mathrm{~km} \cdot \mathrm{h}^{-1}$ para direcionar o fogo, como ocorreu nesse experimento. Brown e Davis (1973) observaram em diversos experimentos de queima nos Estados Unidos da América que, na maioria das vezes, a velocidade de propagação em queimas contra o vento variou entre $0,009 \mathrm{e} 0,018 \mathrm{~m} \cdot \mathrm{s}^{-1}$, valores muito similares aos observados neste experimento.

A análise estatística não detectou diferença significativa entre as médias de altura de chamas das queimas a favor e contra o vento. Os valores médios 0,8 e 1,3 m estão dentro dos limites recomendados para condução do fogo com segurança (FERNANDES et al., 2002). Existe uma forte associação entre as dimensões da chama e a intensidade do fogo. Vários pesquisadores desenvolveram modelos para estimar a intensidade do fogo mediante essa correlação (BYRAM, 1959, BIDWELL; ENGLE, 1991, BATISTA; SOARES, 1993, BEUTLING et al., 2012). 
A intensidade do fogo também variou significativamente entre as queimas a favor e contra o vento. A favor do vento, a variação foi de $62,50 \mathrm{a} 372,95 \mathrm{kcal} \cdot \mathrm{m}^{-1} \cdot \mathrm{s}^{-1}$ (média de $210,53 \mathrm{kcal} \cdot \mathrm{m}^{-1} \cdot \mathrm{s}^{-1}$ ). Na literatura são encontrados valores muito distintos sobre a intensidade do fogo em vegetação de campos. Bidwell e Engle (1990), em experimentos de queimas a favor do vento em pradarias dos EUA, obtiveram valores de intensidade variando entre 17,93 e $663,96 \mathrm{kcal} \cdot \mathrm{m}^{-1} \cdot \mathrm{s}^{-1}$. Fidelis et al. (2010) determinaram médias de $22,35 \mathrm{kcal} . \mathrm{m}^{-1} \cdot \mathrm{s}^{-1}$ para uma área com queima frequente e de $42,79 \mathrm{kcal} . \mathrm{m}^{-1} \cdot \mathrm{s}^{-1}$ para uma área com mais de cinco anos sem queima, ambas a favor do vento. No estudo de Miranda et al. (1996), foram registrados valores entre 299,99 e $3.405,95 \mathrm{kcal} . \mathrm{m}^{-1} \cdot \mathrm{s}^{-1}$ e média de $995,33 \mathrm{kcal} . \mathrm{m}^{-1} . \mathrm{s}^{-1}$. Fidelis et al. (2010) citam os seguintes valores obtidos por diversos pesquisadores: 6,68 a $4.276,53 \mathrm{kcal} . \mathrm{m}^{-1} . \mathrm{s}^{-1}$ para as savanas africanas; 36,06 a $2.200,72 \mathrm{kcal} \cdot \mathrm{m}^{-1} \cdot \mathrm{s}^{-1}$ para a savana australiana; 23,64 a $273,95 \mathrm{kcal} . \mathrm{m}^{-1} \cdot \mathrm{s}^{-1}$ para os campos limpos da Austrália;7,40 a 2.813,12 $\mathrm{kcal} \cdot \mathrm{m}^{-1} \cdot \mathrm{s}^{-1}$ para as pradarias dos Estados Unidos; 10,27 a $265,59 \mathrm{kcal} . \mathrm{m}^{-1} \cdot \mathrm{s}^{-1}$ para as charnecas (áreas pantanosas) da Escócia; 95,06 a 112,73 $\mathrm{kcal} . \mathrm{m}^{-1} . \mathrm{s}^{-1}$ para as Savanas baixas da Venezuela; 46,09 a $538,11 \mathrm{kcal} \cdot \mathrm{m}^{-1} \cdot \mathrm{s}^{-1}$ para as savanas altas venezuelanas e 678,80 a $3.916,59 \mathrm{kcal} \cdot \mathrm{m}^{-1} \cdot \mathrm{s}^{-1}$ para o Cerrado brasileiro.

Nas queimas realizadas contra o vento, os valores obtidos foram menores, com média de 50,68 $\mathrm{kcal} . \mathrm{m}^{-1} \cdot \mathrm{s}^{-1}$, variando entre $18,48 \mathrm{e} 82,15 \mathrm{kcal} . \mathrm{m}^{-1} . \mathrm{s}^{-1}$. Nas queimas contra o vento realizadas por Bidwell e Engle (1991), nas pradarias dos Estados Unidos, foram observados valores médios de intensidade de $23,18 \mathrm{kcal} \cdot \mathrm{m}^{-1} \cdot \mathrm{s}^{-1}$, variando de 7,41 a $34,89 \mathrm{kcal} \cdot \mathrm{m}^{-1} \cdot \mathrm{s}^{-1}$.

A intensidade do fogo, calculada por meio da equação de Byram (1959), tem demonstrado ser um parâmetro muito útil na descrição do comportamento do fogo, além de servir como um índice de referência para se visualizar e comparar as taxas de energia liberadas por diferentes tipos de queimas e/ou incêndios (SOARES; BATISTA, 2007).

Em relação ao calor liberado por unidade de área, foram obtidos os valores de 4.030,88 kcal.m ${ }^{-2}$ nas queimas a favor do vento e de $4.373,45 \mathrm{kcal} . \mathrm{m}^{-2}$ nas queimas contra o vento. Miranda et al. (1996) encontraram valores de $1.999,85$ a $3.405,94 \mathrm{kcal} . \mathrm{m}^{-2}$, em experimento realizado a favor do vento em vegetação de Cerrado (Savana), valores considerados muito próximos aos determinados para as savanas africanas. Essa variável do comportamento do fogo é um parâmetro importante na avaliação dos efeitos do fogo sobre o solo e sobre a emissão de partículas na atmosfera. Geralmente, quanto maior a velocidade de propagação do fogo, menor é a quantidade de energia dirigida para as camadas internas do solo. Ao contrário, quanto mais lenta a propagação do fogo, maior é quantidade de energia concentrada nesse local. Os maiores valores de calor liberado observados nas queimas contra o vento, quando comparados com a queima a favor do vento, são devidos à menor velocidade de propagação nesse tipo de queima.

\section{CONCLUSÕES}

Considerando-se que as queimas controladas foram realizadas dentro dos limites das condições ambientais recomendadas pelas normas para o manejo do fogo, adotadas internacionalmente, pode-se concluir que:

- As queimas controladas em vegetação de Estepe realizadas dentro dos critérios estabelecidos de planos de queima são viáveis e seguras sob o ponto de vista de perigo de incêndios;

- As características do comportamento do fogo foram similares às verificadas em resultados de experimentos de queima em vegetação de Estepe de outras regiões do Brasil e do mundo;

- Os parâmetros intensidade e velocidade de propagação, calor liberado e altura das chamas puderam ser quantificados com facilidade e precisão, permitindo descrição adequada do comportamento do fogo;

- Os valores do comportamento do fogo observados nesta pesquisa são compatíveis com a maioria dos resultados verificados em pesquisas similares realizadas em outras regiões e são fundamentais para avaliar os efeitos do fogo na dinâmica da vegetação pós-fogo em vegetação de estepe;

- A queima contra o vento foi a que apresentou melhores resultados para a vegetação de Estepe, pois os valores de intensidade do fogo e de altura das chamas encontram-se dentro dos limites aceitáveis de danos à vegetação. Também a baixa velocidade de propagação permite um melhor controle do fogo, evitando sua fuga e geração de incêndios. 


\section{AGRADECIMENTOS}

Os autores agradecem ao proprietário da RPPN Caminho das Tropas, Sr. Luiz Eduardo Veiga Lopes Jr. pela disponibilização da área para a realização do estudo, ao Dr. Ernandes Aparecido Saraiva, pós-doutorando de Engenharia Florestal e aos estagiários do Laboratório de Incêndios Florestais do Curso de Engenharia Florestal da UFPR pelo auxílio nos trabalhos de campo.

\section{REFERÊNCIAS}

BATISTA, A. C. Incêndios florestais. Recife: Imprensa Universitária da UFRPE, 1990. 115 p.

BATISTA, A. C.; SOARES, R. V. Avaliação do comportamento do fogo em queimas controladas sob povoamentos de Pinus taeda. Floresta, Curitiba, V. 25, p. 31 - 42, 1995.

BEUTLING, A.; BATISTA, A. C.; SOARES, R. V. Fire behavior modeling based on simulated field plots. WIT Transactions on Ecology and the Environment, London, v. 158, p. 27 - 37, 2012.

BIDWELL, T. G.; ENGLE, D. M. Behavior of headfires and backfires on tallgrass prairie. In: INTERNATIONAL SYMPOSIUM FIRE AND ENVIRONMENT: ECOLOGICAL AND CULTURAL PERPECTIVES, 1990, Knoxville, EUA. Proceedings... Knoxville: USDA Forest Service, 1991. p. 344 350 .

BROWN, A. A.; DAVIS, K. P. Forest fire: control and use. New York: McGraw-Hill, 2nd. ed., 1973. $686 \mathrm{p}$.

BYRAM, G. M. Combustion of forest fuels. In: DAVIS, K. P. Forest fire: control and use. New York: Mc Graw Hill, 1959. p. 77 - 84.

DE RONDE, C.; GOLDAMMER, J. G.; WADE, D. D.; SOARES, R. V. Prescribed fire in industrial plantations. In: GOLDAMMER, J. G. (Ed.) Fire in the tropical biota: ecosystem processes and global challenges. Berlin: Springer-Verlag, 1990. p. 216 - 272 (Ecological Studies, v. 84).

FERNANDES, P.; LOUREIRO, C. Handbook to plan and use prescribed burning in Europe. Universidade de Trás-os-Montes e Auto Douro, Vila Real-Portugal, 2010. 37 p. (Project Fire Paradox).

FERNANDES, P.; BOTELHO, H.; LOUREIRO, C. Manual de formação para a técnica do fogo controlado. Vila Real: UTAD, 2002. 144 p.

FIDEliS, A.; DELGADO-CARTAY, M. D.; BLANCO, C. C.; MÜLlER, C. S.; PILlAR, V. D.; PFADENHAUER, J. Fire intensity and severety in brazilian campos grassland. Interciencia, Caracas, v. 35, n. 10, p. 739 - 745, 2010.

FUNDAÇÃO ABC. Sistema de monitoramento agrometeorológico. Disponível em: <http://sma. fundacaoabc.org.br/monitoramento/grafico/diario>. Acesso em: 15/01/2013.

GARNICA, J. G. F., GONZALEZ, D. A. M.; SOLORIO, J. D. B. Forest fire behavior in prescribed burns under different environmental conditions in México. Forest Ecology and Management, Amsterdam, v. 234, n. 1, p. 131, 2006.

GRIFFIN, G. F.; FRIEDEL, M. H. Effects of fire on central Australian rangelands I: fire and fuel characteristics and changes in herbage and nutrients. Australian Journal of Ecology, Carlton, v. 9, n. 4, p. $381-393,1984$.

INSTITUTO AMBIENTAL DO PARANÁ (IAP) Unidades de conservação do Paraná: RPPN Reserva Particular do Patrimônio Natural. Disponível em: <http://www.uc.pr.gov.br/modules/conteudo/conteudo. php?conteudo=131>. Acesso em: 15/01/2013.

INSTITUTO AGRONÔMICO DO PARANÁ (IAPAR) Mapas climáticos do estado do Paraná. Disponível em: <http://www.pr.gov.br/iapar/sma/Rosa_dos_ventos.htm〉. Acesso em: 15/01/2013. 
KUÇUK, O.; BILGILI, E.; SAGLAM, B.; BASKAYA, S.; DINÇ DURMAZ, B. Some parameters affecting fire behavior in anatolian black pine slash. Turk J Agric For, Ankara, v. 32, p. 121 - 129, 2008.

LEITE, P. F. Contribuição ao conhecimento fitoecológico do sul do Brasil. Ciência \& Ambiente, Santa Maria, v. 24, p. 51 - 63, 2002.

LEVINE, J. S. Biomass burning and global change: biomas burning in South America, Southeast Asia, and temperate and boreal ecosystems, and the oil fires of Kuwait. Massachussts Institute of Technology Press, Cambridge, EUA, v. 2, p. 561 - 568, 1996.

MAACK, R. Geografia física do estado do Paraná. Curitiba: BADEP/UFPR/IBPT, 1981. 450 p.

MIRANDA, H. S.; ROCHA E SILVA, E. P.; MIRANDA, A. C. Comportamento do fogo em queimadas de campo sujo. In: MIRANDA, H. S.; SAITO, C. H.; DIAS, B. F. de S. (Org.) Impactos de queimadas em áreas de cerrado e restinga. Brasília: UnB, ECL, 1996. p. 1 - 10.

PIVELLO, V. R. The use of fire in the cerrado and amazonian rainforests of Brazil: past and present. Fire Ecology, v. 7, n. 1, p. 24 - 39, 2011.

PIVELLO, V. R.; COUTINHO, L. M. Transfer of macro-nutrients to the atmosphere during experimental burnings in an open cerrado (brazilian savanna). Journal of Tropical Ecology, Cambridge, v. 8, n. 4, p. 487 - 497, 1992.

RIBEIRO, G. A.; LIMA, G. S.; OLIVEIRA, A. L. S.; CAMARGOS, V. L.; MAGALHÃES, M. U. Eficiência de um retardante de longa duração na redução da propagação do fogo. Revista Árvore, Viçosa, v. 30, n. 6, p. 1025 - 1031, 2006.

SOARES, R. V. Incêndios florestais: controle e uso do fogo. Curitiba: FUPEF, 1985. 213 p.

SOARES, R. V. Queimadas controladas: prós e contras. In: FÓRUM NACIONAL SOBRE INCÊNDIOS FLORESTAIS, 1., 1995, Piracicaba. Anais, Piracicaba: IPEF, 1995. p. 6 - 10.

SOARES, R. V.; BATISTA, A. C. Incêndios florestais: controle, efeitos e uso do fogo. Curitiba, 2007. $264 \mathrm{p}$.

SOUZA, L. J. B; SOARES, R. V.; BATISTA, A. C. Modelagem do material combustível superficial em povoamentos de Eucalyptus dunnii, em Três Barras, SC. Cerne, Lavras, v. 9, p. 231 - 245, 2003.

VEGA, J. A. Investigacion sobre control de incendios en España. In: REUNIÃO TÉCNICA CONJUNTA FUPEF/SIF/IPEF, 4., 1996, Curitiba; CURSO DE ATUALIZAÇÃO EM CONTROLE DE INCÊNDIOS FLORESTAIS, 2., 1996, Curitiba. Anais, Curitiba: FUPEF, 1996. p. 40 - 56. 
